\title{
Design of logistic system using Tecnomatix software
}

\author{
Beáta Furmannová ${ }^{1}$, Gabika Gabajová ${ }^{1}$, Vladimír Vavrík ${ }^{1}$ \\ ${ }_{1}$ University of Žilina, Faculty of Mechanical Engineering, Department of Industrial \\ Engineering \\ Univerzitná 1, 01026 Žilina, Slovakia \\ beata.furmannova@fstroj.uniza.sk \\ gabika.gabajova@fstroj.uniza.sk \\ vladimir.vavrik@fstroj.uniza.sk
}

\begin{abstract}
Anotace: This article deals with the logistics planning tool. A digital enterprise tool for a complex PLM solution is used, namely the Tecnomatix Process Designer software. It is a description of the logistics module environment, main workflows and basic functions of this module.
\end{abstract}

\section{Introduction}

The designers of modern production and logistics systems are already trying to incorporate in their design the ability to quickly adapt to changing market conditions, the ability to make autonomous decision-making, self-organization and self-optimization of production and logistics processes concerning their safety. Smart logistics and production systems are part of the new Industry 4.0 concept and are at the heart of factory of the future. Designing intelligent production and logistics systems requires the application of digital technologies throughout the entire production system lifecycle. The concept of using a software environment to design, plan and manage business processes and systems in a virtual environment is referred to as a digital factory. Designing production and logistics systems is one of the core activities in the digital factory concept. Its aim is to assess the relationships between the individual elements of production systems in terms of time and space requirements of the technological, handling, control and other activities necessary for the realization of a rational production process and subsequently to propose a suitable spatial and time structure of the production process.

Design of the logistics system represents an important part of the production system design. Production can`t exist without supply of material from the warehouse to the workplace and transport of products from the workplace to the warehouse of finished products. Therefore it is necessary to create appropriate routes, to define appropriate transported quantities, to choose the technology to be used in warehouses for transport, etc. New technologies are developed rapidly and enterprises have to think about their implementation into the strategy. 
Digital factory technologies are important not only in the phase of final visualization of digital projection outputs but their application begins in the phases of creating and optimizing the 3D model of the manufacturing system. There are many problems and risks during the process of designing production and logistics systems. Using software solutions reduces these risks significantly and ensures the security of the future production system.

Tecnomatix Process Designer is a digital manufacturing solution for manufacturing process planning in a 3D environment. It facilitates the design and validation of manufacturing processes from concept and detailed engineering through production planning. Process Designer is a major enabler of speed-to-market by allowing manufacturing organizations to bridge product and process design with integrated authoring capabilities that leverage digital product development resulting in faster launch and higher production quality.

\section{Tecnomatix Process Designer}

Tecnomatix product portfolio, can be used to represent a "digital factory" on the computer. This is not just about controlling individual machine tools. The interaction of all manufacturing resources in production is what is important - for instance, whether robots work together smoothly and can easily access all tools. Long before the manufacturing begins, Tecnomatix users are able to simulate the material flow and figure out the optimal assembly line speed.

Tecnomatix Process Designer and Process Simulate is a digital manufacturing solution for manufacturing process planning and validation in a 3D environment. Process Designer is a major enabler of speed-to-market by allowing manufacturing organizations to bridge product and process design with integrated authoring capabilities that leverage digital product development. Process Simulate allows organizations to virtually validate manufacturing concepts upfront - throughout the lifecycle of new product introductions. The ability to leverage 3D data of products and resources facilitates virtual validation, optimization and commissioning of complex manufacturing processes, resulting in faster launch and higher production quality.

The main features are [1]:

- Process modelling and verification (pert and Gantt charts, schematic and table views, time estimation, cost estimation and tracking, line design, alternative planning, process variants management, documentation authoring, application customizations).

- Integrations with time standards systems.

- Automatic generation of assembly structure or assembly process.

- Line balancing.

- Tasks management and collaboration. 
- 2DI3D system integrations.

- Manufacturing features management.

- 3D simulation.

- Static and dynamic collision detection.

- $2 \mathrm{D}$ and 3D sections.

- 3D measurements.

- Sequencing of operations.

- Assembly and robotic path planning.

\section{Logistics in Tecnomatix Process Designer}

Part of this solution is the Logistics module, which provides users with a basic data model of logistic objects, allowing them to build logistics-specific planning projects and manage the relevant data.

In the first phase we can start with network planning. In this phase logistics planners are allowed to define logistic networks and to calculate production rates per part family. This requires taking a few steps. As first setup the network structure. Then setup the part structure (BOM). Setup one resource per logistic plant. Assign the resource that represents the logistic plant to the logistic plant of the network structure. Assign the produced parts to the logistic plant project and define the production rate. As the last create part families automatically out of the BOM. One part family is created for each part

in the BOM, and the relevant part is assigned to the part family. Alternatively, the part families can be defined in a library and copied below the logistic project. Based on the information you defined, the system calculates the required transportation relations between the plants. The calculated transportation relations include the calculated number of products and required parts. [2] 

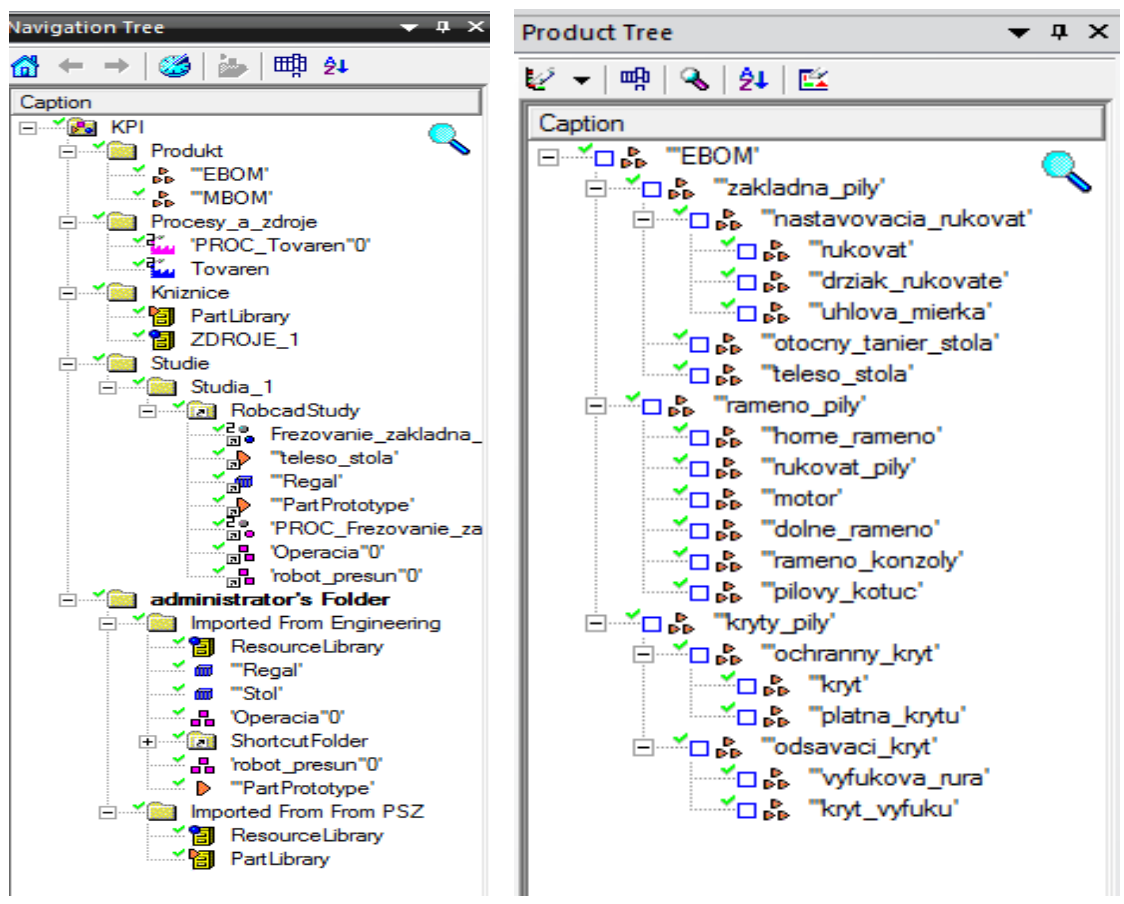

Figure 1 - Network and part structure - BOM (Author)

Logistics planners can open the Process Check tab (Figure 2) to view progress of the logistic planning. The Process Check tab offers the following predefined checks [3]:

- Parts assigned to LogProcess: Is there at least one part assigned to the LogProcess object?

- Container assigned LogProcess: Is there exactly one Container assigned to the LogProcess object?

- Container assigned to logistics operations: Is there exactly one Container assigned to the Move/Store operations of the supply chain of the LogProcess?

- Supply Chain defined: Is there a supply chain defined for the LogProcess?

- Supplier assigned: Is a supplier assigned to the LogProcess?

- Areas assigned to store operations: Are there LogAreas assigned to the store operations of the supply chain?

- Times assigned to logistics operations: Are there times assigned to the logistics operations (do all logistic operations of the supply chains have an allocated time $>0$ ).

- General check that assigned container, supplier, areas, etc., are from the correct defined library: The system checks whether all assigned resources of the following types - LogArea, LogContainer, Supplier, Vehicle, Transporter, SupplyChains (for linked supply chains) belong 
to the respective library of the plant, under which the LogProcess resides. The libraries are taken from fields such as LogPlant, LibrarySuppliers, etc.

- Consistency check to verify the logistics plan against the production plan to find any inconsistencies. The check is based on the use of the same parts and logistics areas by both production planning and logistics planning. A logistics plan is consistent if the parts and the corresponding logistics areas are assigned to the same station as in the production plan.

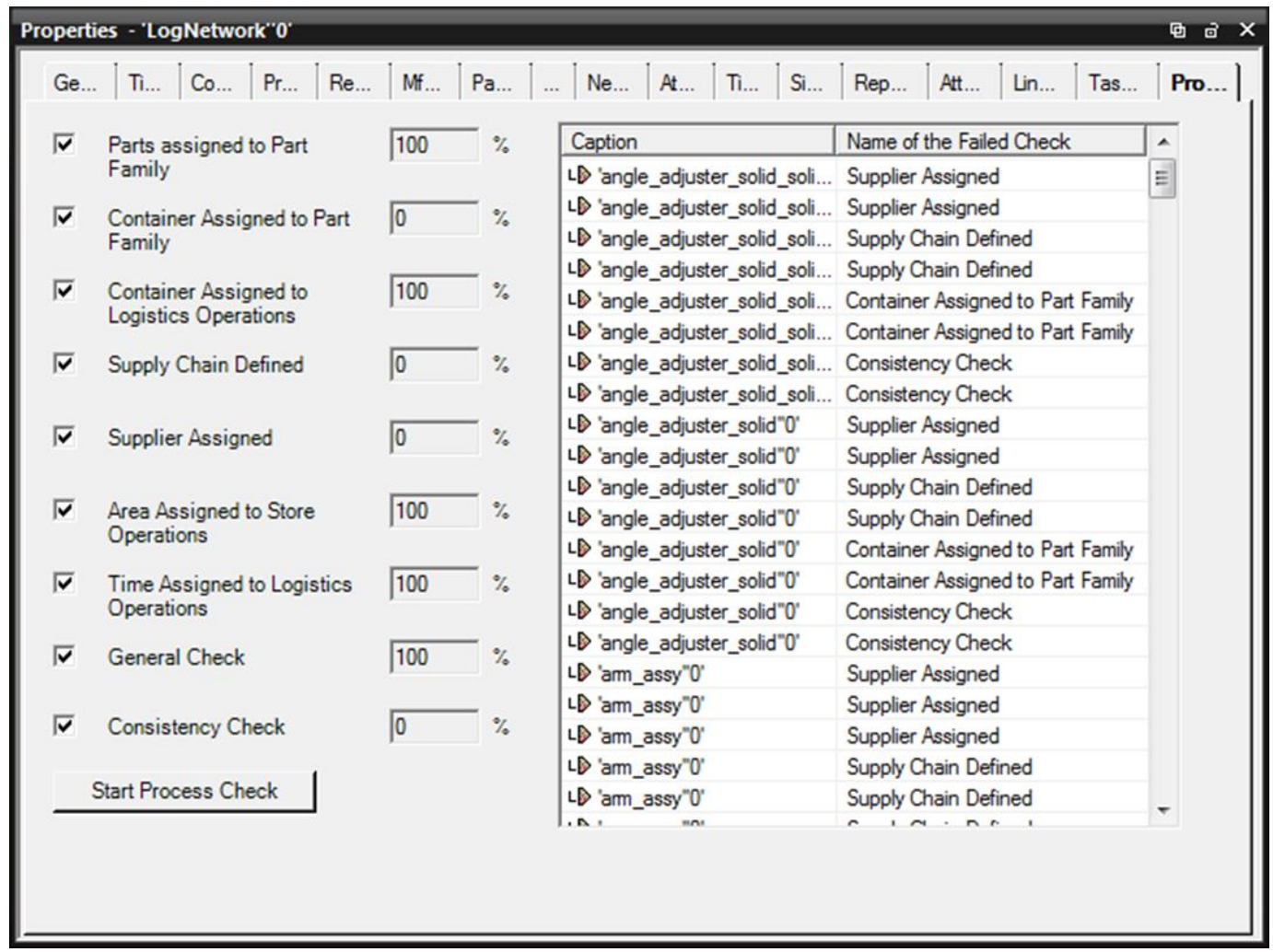

Figure 2 - Process Check table (Author)

Logistics areas and tracks features enable to build a logistic path network and logistics areas. Logistics planners can describe full area and path networks by drawing areas and tracks and connecting them, using connection points, to other logistic areas or tracks. Using these commands logistics planners can define the direction of the tracks, and to set them as one-way or two-way. Defined path networks can be used as the basis for calculations of route and transport time. [4]

Using basic commands for drawing, deleting, showing and hiding all logistics areas and logistics tracks they can be seen and designed directly in the 3D layout of production system (Figure 3). 


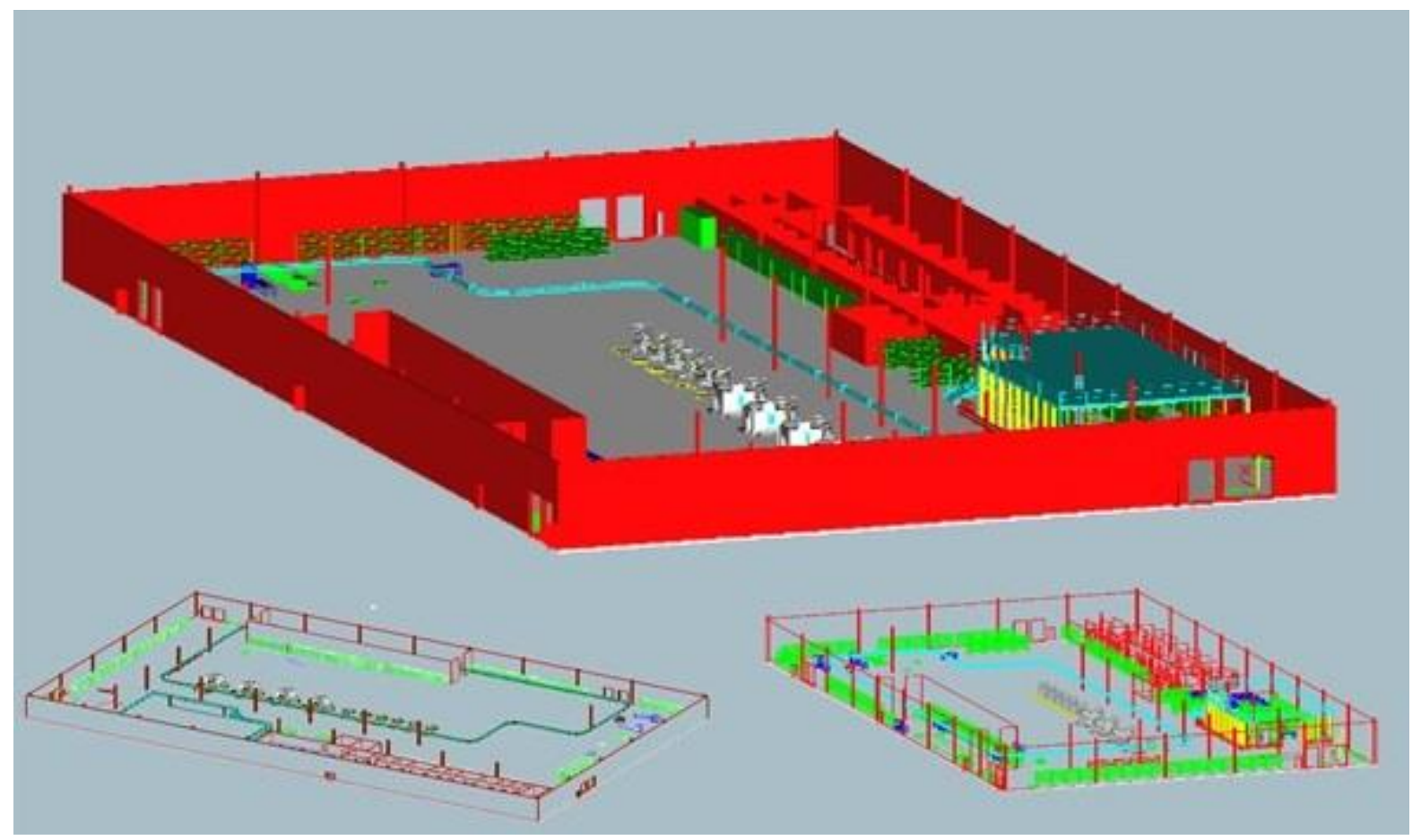

Figure 3-3D layout of production system with logistics areas (Author)

\section{Conclusion}

The digitization in the 21st century brings with it the need to design intelligent logistics systems. Logistics as a whole is a supporting activity that needs to do to receive, store or transport the goods to the final customer. From experience we can say that this is an area where we can save considerable financial resources with the right management and organization system. Logistics is an article without which nothing would work in the company.

In recent years, the concept of the Digital factory has come to the forefront that significantly affects modern business processes. One of its tools is Tecnomatix Process Designer that provides a platform for digitizing production process planning in 3D environment. There is a possibility optimize material flows, use resources and logistics for all levels of planning, from individual machines, production lines, through local factories, to a global manufacturing plant.

Human with his knowledge is still the most important element of successful design and planning of logistics systems. His timely logistics analysis and optimal supply chain definition is the key to efficient logistics processes. By using digital tools, companies can prevent unintentional failure in case of incorrect material flow design and verify your designs before integrating them into reality.

This article describes the main elements of logistics in Tecnomatix Process Designer environment. Based on experiences in the implementation of intelligent logistics systems in digital environment, it will be possible in the future to affect up to $80 \%$ of the costs related to the preparatory phase of the 
solved project in logistics. Importance of digital technologies is increasing significantly nowadays. Therefore, future logistics systems will be massively supported by technologies stemmed from the Industry 4.0 technological revolution. The use of Tecnomatix Process Designer enables the quality of the design itself to be improved in terms of future cost, productivity, safety and environmental performance of the future logistics system.

\section{Acknowledgement}

This paper was supported by research project KEGA 017ŽU-4/2019 Digitalizácia $v$ priemyselnom inžinierstve pre študentov technického zamerania.

\section{References}

[1] Siemens PLM Solutions. Tecnomatix, [online] 2019, [cit. 5.8.2019] http:// www.siemens.com/tecnomatix

[2] Plinta, D., Krajčovič, M. Production system designing with the use of digital factory and augmented reality technologies. In: Advances in Intelligent Systems and Computing, 2016, Vol. 350, p. 187-196. ISSN 2194-5357.

[3] Krajčovič, M. et al. Intelligent Manufacturing Systems in concept of digital factory. In: Communications: scientific letters of the University of Žilina, 2013, Vol. 15, No. 2, p. 77-87. ISSN 1335-4205.

[4] Rakyta, M., Fusko, M., Haluška, M., Grznár, P. Maintenance support system for reconfigurable manufacturing systems. In: Annals of DAAAM Proceedings of the 26-th DAAAM International symposium on intelligent manufacturing and automation. Vienna: DAAAM International Vienna, Austria, 2016, p. 1102-1108. ISBN 978-3-902734-07-5. 